\title{
Estigmas da obesidade no contexto das organizações: abominação, fracasso e incapacidade
}

\section{Obesity stigma in the context of organizations: abomination, failure and disability}

\author{
VITÓRIA REZENDE LOPES* \\ CINTIA RODRIGUES DE OLIVEIRA MEDEIROS**
}

\section{RESUMO}

A obesidade tornou-se uma preocupação da sociedade contemporânea e tem sido objeto de interesse de pesquisas em diversas áreas do conhecimento. No campo da administração em geral - e mais especificamente no de estudos organizacionais e gestão de pessoas -, o tema tem sido marginalizado, deixando lacunas e questões em aberto. Neste artigo temos o objetivo de caracterizar, conforme a visão de pessoas obesas, como o preconceito se manifesta na esfera do trabalho. Para tanto, realizamos uma pesquisa por meio de um formulário disponibilizado para um grupo de usuários da rede social on-line Facebook que realizaram o procedimento de cirurgia bariátrica ou gastroplastia. No total 290 pessoas preencheram o questionário. Para o exame das respostas, utilizamos a análise de frequência e a análise de conteúdo temática. As categorias finais identificadas foram: (1) a abominação do corpo obeso; (2) o corpo obeso como fracasso; e (3) a incapacidade do corpo obeso. Os resultados apontam para a relação entre a construção social do corpo na sociedade contemporânea e o estigma vivenciado pelos obesos, sobretudo no contexto organizacional, sinalizando para um campo promissor de estudos.

Palavras-chave: Obesidade; corpo; estigma; discriminação; organizações.

* Doutora em Administração de Empresas (FGV/EAESP0, Professora Adjunta da FAGEN/ UFU, e-mail: cintia@ufu.br

** Graduanda em Gestão da Informação, FAGEN/UFU, e-mail: vrezendelopes@gmail.com 


\section{Abstract}

Obesity has become a concern of contemporary society and has been the subject of interest of research in various fields of knowledge. In the field of administration in general and more specifically in the areas of organization studies and personnel management, this issue has been sidelined, leaving gaps and open questions. In this research, we aim to characterize, as the vision of obese people, as the prejudice against those manifested in the sphere of labor. Therefore, we conducted a survey through a form available to a group of users online social network Facebook, whose participants underwent bariatric or gastric bypass surgery procedure, and it was completed by 290 members. For the analysis of the responses, we use the frequency analysis and content analysis. We identify three final categories: (1) the abomination of the obese body; (2) the obese body as failure; and (3) the inability of the obese body. The survey results point to the relationship between the social construction of the body in contemporary society and the stigma experienced by obese, especially in the organizational context, signaling a promising field of study.

Keywords: Obesity; boy; stigma; discrimination, organizations.

\section{INTRODUÇÃo}

A diversidade no trabalho tem recebido atenção de pesquisadores que trilham caminhos diversos para tratar das diferenças, da (in)tolerância, dos preconceitos e outras temáticas, como, por exemplo, as barreiras que pessoas categorizadas em determinados grupos enfrentam nos processos de seleção e promoção no trabalho. Neste artigo, centramos nossa discussão na obesidade, uma característica que tem sido alvo de preconceitos e atitudes discriminatórias (BRAY, 2009). Casos não faltam sobre o modo como as pessoas obesas são ignoradas e desconsideradas em processos sociais ou vivenciam situações de agressão, discriminação e rejeição (FOLHA DE S.PAULO, 1997; FERNANDES, 2001; VIEIRA; COHEN, 2014). Em contrapartida, mesmo em menor grau, surgem protestos de pessoas nessa condição que se mobilizam para dizer não ao preconceito contra a obesidade (FOLHA DE S.PAULO, 2014) e também para afirmar que "Fat is beautifuP", o slogan de um movimento surgido em Los Angeles na década de 1990 (STENZEL, 2003). 
A enunciação de que o "excesso de gordura corporal" seria uma doença, especialmente no Ocidente, tem datação recente. Foi a partir do final do século XVIII que a patologização da obesidade não se justificou em evidências científicas, mas, sim, em princípios estéticos, políticos, religiosos e socioculturais provenientes de momentos históricos anteriores (SANTOLIN; RIGO, 2015). Porém, desde a última década do século XX, a desvalorização estética do corpo gordo, historicamente situada e culturalmente construída, se intensificou, originando um preconceito conhecido como gordofobia.

$\mathrm{Na}$ contemporaneidade, a obesidade é vista como uma doença endêmica (COPPINI, 2015) que ameaça o bem-estar da sociedade em geral e, de forma particular, o ambiente de trabalho. Porém, a pessoa obesa carrega ainda um peso social, pois os padrões de aparência elegidos pela dinâmica social ao investir no corpo magro como sinônimo de saúde e beleza, responsabilizam o indivíduo pela administração de seu corpo, ocasionando efeitos concretos sobre as oportunidades e restrições experimentadas por pessoas que não correspondem a tais padrões.

A estigmatização da obesidade é reforçada no contexto contemporâneo, pois é nele que se produz a massificação do que é estético, e, sobretudo, do que deve ser almejado, ao conferir lugar de destaque, sucesso e poder aos indivíduos que estão inseridos nos modelos socialmente estabelecidos de beleza (BUCARETCHI, 2003). Nesse sentido, Felerico (2009, p. 2) destaca que "ter um corpo 'perfeito', 'bem delineado', 'em boa forma' consagra o homem e representa a vitória sobre a natureza, o domínio além do seu corpo, o controle do seu próprio destino". Já "a gordura, a flacidez, o sedentarismo simbolizam a indisciplina, o descaso", fazendo com que as pessoas se sintam “culpadas pelo 'fracasso' do próprio corpo". Portanto, o corpo magro se tornou um valor cultural, sinônimo de saúde e beleza, e, no mesmo compasso, a obesidade passou a ser considerada uma doença endêmica que ameaça o bem-estar da sociedade em geral, trazendo implicações também para o ambiente de trabalho.

Nas organizações, o preconceito contra os obesos se manifesta tanto na seleção para contratação quanto na remuneração desses profissionais, como mostra a pesquisa realizada pelo Grupo Catho, em 2005, na qual 65\% dos executivos brasileiros afirmaram preferir contratar pessoas que não estejam fora do peso (PATARI, 2015). Nos níveis hierárquicos mais elevados, como cargos de presidência, diretoria, gerência e supervisão, esse tipo de discriminação é ainda mais evidente. Com relação ao impacto negativo na remunera- 
ção desses profissionais, cada ponto adicional no Índice de Massa Corpórea (IMC) chega a reduzir R $\$ 92$ do salário mensal de um gerente obeso, quando comparado com o de uma pessoa magra (PATARI, 2015).

Diante desses fatos, neste artigo abordamos a obesidade no contexto das organizações, com o objetivo de investigar como o preconceito contra os obesos, conforme a visão dessas pessoas, se manifesta. Como método de procedimento, conduzimos a aplicação de um formulário para membros de um grupo da rede social on-line Facebook que passaram pelo procedimento de cirurgia bariátrica ou estão se preparando para realizá-lo.

O artigo está estruturado em quatro seções. Na primeira, introduzimos a revisão da literatura sobre a construção social do corpo na sociedade contemporânea, seguida por uma discussão acerca do processo socialmente construído de estigmatização; na segunda, descrevemos os procedimentos metodológicos da pesquisa; na terceira, analisamos o material empírico obtido; e na quarta, propomos uma discussão a respeito daquilo que foi levantado. Nossas considerações finais encerram o artigo.

\section{OBESIDADE E CORPO}

Esta pesquisa se ancora em dois recortes teóricos: a construção social do corpo e o processo de estigmatização. Eles serão apresentados e discutidos a seguir.

\subsection{0 corpo: na história e na contemporaneidade}

A espetacularização do discurso midiático e a prosperidade da "sociedade do consumo" (BAUMAN, 2008) tornaram a preocupação com o corpo um dos valores predominantes na sociedade contemporânea. O corpo humano é socialmente construído (SYNNOTT, 1992) e assumiu significados diferentes ao longo do tempo, resultantes de processos históricos que representavam não apenas os condicionamentos sociais e culturais da época, mas também fatores políticos, econômicos, científicos e religiosos. Daolio (1995, p. 105) entende que "No corpo estão inscritas todas as regras, todas as normas e todos os valores de uma sociedade específica, por ser ele o meio de contacto primário do indivíduo com o ambiente que o cerca"; isto é, por meio do corpo, os indivíduos se manifestam no mundo (WANDERLEY; FERREIRA, 2010). Os modelos estéticos contemporâneos têm relação com as acepções corporais concebidas nas raízes históricas da civilização ocidental; portanto, 
é válido ressaltar certas fases da história humana para conhecer os sentidos construídos para o corpo no presente.

$\mathrm{Na}$ Grécia Antiga, o corpo era visto como elemento de glorificação e de interesse do Estado (SIEBERT, 1995) e então valorizado pela capacidade atlética, saúde e fertilidade. Ainda, a presença corporal não era apenas um atributo necessário para a sobrevivência do homem primitivo, mas também considerada sua identidade pessoal e social, construindo e regulamentando as relações sociais do indivíduo, o qual exercia domínio e poder se tivesse, essencialmente, determinadas qualidades corporais (GONÇALVES, 1994). Um grego cujo corpo fosse simétrico, forte, veloz e esteticamente belo tornava-se um elemento superior naquela sociedade e desempenhava funções sociais importantes.

Essa relação do homem com a sua corporeidade foi alterada na Idade Média, pois o dogmatismo religioso reprimia e condenava qualquer manifestação corporal que não estivesse dentro dos princípios da Igreja, como, por exemplo, o culto ao corpo, o qual era visto como corrupto e pecaminoso. $\mathrm{Na}$ sociedade tradicional, características físicas como altura, cor da pele e peso corporal doutrinavam o sistema de castas (PELEGRINI, 2006).

$\mathrm{Na}$ Renascença, movimento antropocêntrico guiado pela razão científica, o corpo foi redescoberto como objeto de estudos e experiências e, como tal, deveria ser manipulado e dominado (GONÇALVES, 1994). O corpo físico, anatômico e biomecânico foi investigado, analisado e descrito (GAYA, 2005), principalmente nas obras de arte. Pelegrini (2006, p. 3) ressalta a linha de pensamento dos ideais renascentistas: "Todas as atividades físicas eram prescritas por um sistema de regras rígidas, visando a saúde corpórea. A obtenção do corpo sadio circundava a dominação do indivíduo: a prática física domava a vontade, contribuindo para tornar o praticante subserviente ao Estado". Nesse cenário favorecido pelo avanço da racionalidade e pelo progresso das ciências, o capitalismo se expandia e se solidificava, bem como o crescente domínio do homem em relação ao próprio corpo (GONÇALVES, 1994). Nessa nova ordem social, o corpo passou, progressivamente, a servir à razão (BARBOSA; MATOS; COSTA, 2011).

No século XVII, com o início da Revolução Industrial, as acepções corporais instituídas pela Renascença foram alteradas. Na lógica de produção capitalista, o corpo do trabalhador ocidental, moldável e passível de exploração era percebido como uma "máquina” cujos movimentos deveriam 
ser disciplinados; também era visto apenas na perspectiva de acúmulo de capital. Com a propagação da forma de produção industrial no século XIX, os movimentos e gestos corporais foram padronizados e instrumentalizados (PELEGRINI, 2006). A esse respeito, Vaz (2006, p. 42) comenta que "durante o capitalismo de produção, que vigorou pelo menos até o início da década de 1960 na maior parte dos países capitalistas, o corpo entrava no mercado como força de trabalho". Isso porque era pensado como força a ser domada e preservada, já que a sua capacidade de produzir era o que mais importava. Ainda conforme Vaz (2006, p. 42), "atualmente, vivemos o capitalismo da superprodução, no qual o problema é consumir o que se produz em excesso comparativamente à necessidade. Desde então, o corpo entra no mercado como capacidade de consumir e ser consumido".

Essa nova noção de corpo, mediada pelos interesses da indústria de consumo, foi fundada no corpo produtor que, necessariamente, deve ter saúde para ser produtivo e precisa se adaptar aos padrões estéticos para consumir melhor (BARBOSA; MATOS; COSTA, 2011). De fato, a representação da beleza estética no capitalismo tardio (século XX) está associada a determinados ideais de saúde, magreza e atitude que garantem ou não a integridade de uma pessoa em termos de aceitação social. Além disso, a busca por um corpo ideal é incentivada pela mídia que expõe os padrões de beleza que, por sua vez, geram a insatisfação com a imagem corporal (DAMASCENO et al., 2006).

$\mathrm{Na}$ sociedade contemporânea, o corpo se torna objeto de consumo, e a valorização da aparência conforme a modelagem dos corpos pelas normas, representações culturais e simbólicas leva as pessoas em direção a um conjunto de práticas para operacionalizar o corpo ideal (WANDERLEY; FERREIRA, 2010). É nesse sentido que Heilborn (2002) afirma que o corpo é uma dimensão produzida pelos efeitos da cultura e não se reduz a uma entidade natural; como Lorber e Martin (2013) defendem, essa visão do corpo passou a ser um julgamento moral. Isso porque quando o corpo contradiz os padrões estabelecidos, a pessoa é vista como dotada de baixo autocontrole e de baixa autoestima. Assim, as características e atributos do corpo valorizados por dada sociedade determinam o modelo desejável de aparência, atribuindo ao corpo um valor de troca ou um capital social na perspectiva de Bourdieu (2007), pois o corpo confere status à pessoa.

Baudrillard (2005) aponta que a "sociedade de consumo" conduz os indivíduos a encararem a ditadura da beleza, da magreza e da saúde como uma escolha pessoal, fazendo com que o corpo se torne uma prisão ou um inimigo 
a ser constantemente domado. Outra característica dessa época é a intolerância com relação à gordura, e a obesidade assume a forma mais representativa de exclusão social, carregada de estereótipos depreciativos (NOVAES, 2006). Assim, os padrões de beleza associados ao corpo magro passam a ser um dever moral cujo fracasso é considerado uma incapacidade individual.

\subsection{0 processo de estigmatização e obesidade}

A obesidade é um atributo físico cuja interpretação, conforme apontam Wanderley e Ferreira (2010), difere nos diferentes contextos históricos e socioculturais. Se no passado o corpo gordo foi associado à ideia de saúde, atualmente, em face das novas concepções acerca do corpo magro, é sinônimo de fracasso e exclusão social. Os obesos, por não se incluírem nos padrões de beleza contemporâneos que cultuam corpos excessivamente magros ou musculosos, não obtêm o reconhecimento e aprovação da sociedade, e são estigmatizados (PUHL; HEUER, 2009).

Tendo em vista a estigmatização que sofrem e o consequente isolamento a que se sujeitam, faz-se necessária a construção de um diálogo sobre o processo socialmente construído de estigmatização, relacionando-o com a temática da obesidade. O termo estigma tem origem na civilização grega e se referia a sinais feitos com fogo ou com cortes nos corpos de indivíduos considerados inaptos para a aceitação social plena. Pode-se dizer que quem apresentava essas marcas corporais era rejeitado pela sociedade, visto ser tido com moralmente defeituoso e representava vergonha e desonra. A palavra foi ressignificada na época do cristianismo, e mais recentemente, já na década de 1960, o sociólogo Erwin Goffman chamou atenção para o tema.

Goffman (1975, p. 6) define estigma como uma característica ou atributo do indivíduo que "o torna diferente de outros que se encontram numa categoria em que pudesse ser - incluído, sendo, até de uma espécie menos desejável - num caso extremo, uma pessoa completamente má, perigosa ou fraca". O autor ressalta que tal característica é um estigma quando, principalmente, tem um efeito de descrédito "e constitui uma discrepância específica entre a identidade social virtual e a identidade social real". De modo mais específico, Goffman (1975, p. 12) explica o conceito de estigma sob a visão de um processo socialmente construído, pelo que "a sociedade estabelece os meios de categorizar as pessoas e o total de atributos considerados como comuns e naturais para os membros de cada uma dessas categorias". Isso porque, como o autor observa, somente são tidos como atributos indesejáveis 
aqueles que não estão de acordo com os estereótipos criados para determinado tipo de pessoa.

Para Goffman (1975, p. 5), as pré-concepções das pessoas normais, como se refere àqueles que estigmatizam, "transformam-se em expectativas normativas, em exigências apresentadas de modo rigoroso"; porém, no cotidiano, tais pré-concepções são ignoradas até que surja uma evidência de que o estranho tem um atributo que o torna uma pessoa "estragada e diminuída".

Segundo Goffman (1975), o conceito de estigma é aplicado a todos os casos em que um atributo observável deprecia o sujeito em seu contexto social, uma vez que os demais membros da sociedade o identificam como menos desejável, diferente, mau, perigoso, inferior ou fraco. Com base nessa definição, Goffman (1975, p. 6) conclui, a respeito do indivíduo:

Assim, deixamos de considerá-lo criatura comum e total, reduzindo-o a uma pessoa estragada e diminuída. Tal característica é um estigma, especialmente quando o seu efeito de descrédito é muito grande algumas vezes ele também é considerado um defeito, uma fraqueza, uma desvantagem [...].

O estigma é, portanto, um traço profundamente depreciativo que, por não corresponder aos padrões estabelecidos pela sociedade, desvaloriza, rejeita e diminui o indivíduo automaticamente identificado por uma marca. Nas palavras de Goffman (1975, p. 7), a pessoa estigmatizada "pode-se impor a atenção e afastar aqueles que ele encontra, destruindo a possibilidade de atenção para outros atributos seus".

Melo (2000, p. 3) observa que o estigma é uma marca que a sociedade imputa ao estigmatizado, limitando e delimitando a sua capacidade de ação, e "quanto mais visível for a marca, menos possibilidade tem o sujeito de tentar romper ou ocultá-la nas suas inter-relações, pois, já identificada, dificilmente poderá reverter a imagem formada anteriormente pelo padrão social". O estigmatizado, por não conseguir relativizar essas diferenças, aceita a rejeição imposta pela sociedade e, ao negligenciar suas qualidades e seus atributos pessoais, reforça a representação social de "incapaz" e "prejudicial" às relações de convivência social. Nesse sentido, para os sujeitos denominados como portadores de um estigma, como Melo (2000, p. 2) afirma, "a sociedade reduz suas oportunidades, esforços e movimentos, não lhes atribui valor, impõe-lhes a perda da identidade social de seres 
individualizados e determina uma imagem deteriorada dentro do modelo que convém à sociedade".

$\mathrm{Na}$ sociedade contemporânea, grupo dos obesos é socialmente marginalizado, pois, por não se enquadrar dentro dos atributos estéticos estabelecidos, é alijado do convívio social (FISCHLER, 1995) e, independentemente de seu status ou conquistas pessoais, sempre será defeituoso aos olhos dos "normais". Isso implica que, para estes, alguém com um estigma não é considerado normal. Nesse recorte, Goffman (1975) discute a caracterização de desacreditado e desacreditável. O primeiro se refere à condição do indivíduo cujas características distintivas já são conhecidas ou evidentes no trato social; já o segundo se refere à condição em que as características do estigmatizado não são conhecidas nem imediatamente percebidas. Na tentativa de acobertar sua condição de estigmatizados, os desacreditados buscam manipular e reduzir as tensões, e os desacreditáveis procuram manipular as informações para ocultar sua marca, o que representa um alto preço psicológico para ambos.

Goffman $(1975$, p. 7) destaca ainda que o estigma pode ocorrer em virtude de três circunstâncias: (1) abominações do corpo, como as diversas deformidades físicas; (2) culpas de caráter individual, como vontade fraca, paixões tirânicas ou não naturais, desonestidade, crenças falsas e rígidas; e (3) estigmas tribais de raça, nação e religião. No caso da obesidade, por suas características biológicas e socioculturais, as condições estigmatizantes mais importantes, conforme a descrição de Goffman (1975), parecem ser a primeira (abominações do corpo) e a segunda (culpas no caráter individual). O corpo obeso é estigmatizado como uma abominação, em função do excesso de gordura, pois sua imagem é tida como deformidade física, situando-se esses na condição de desacreditados. O obeso pode, ainda, ser estigmatizado como o fracasso, que faz referência à personalidade ou comportamento do indivíduo, já que, na contemporaneidade, os obesos são considerados responsáveis pela própria condição (LEVAY, 2013).

Pesquisando a obesidade como estigma, Rothblum (1992), Puhl e Brownell (2001) e Puhl e Heuer (2009) identificam que os obesos são estigmatizados em diversos ambientes de trabalho, como educação, cuidados com a saúde, bem como em relacionamentos familiares e amorosos e até mesmo pela mídia. Conforme os autores, essas pessoas são consideradas sem disciplina, preguiçosas, menos competentes, emocionalmente instáveis, e esses estereótipos podem afetar a contratação, promoção e demissão daqueles que têm excesso de peso. 


\section{Procedimentos da PESQuisa}

Esta é uma pesquisa de natureza qualitativa, embora sejam utilizados, de modo complementar, recursos para quantificar algumas das respostas obtidas. Os participantes são 290 pessoas adultas, de ambos os sexos, residentes em várias regiões do Brasil, membros de um grupo de usuários da rede social on-line Facebook que realizaram cirurgia bariátrica ou gastroplastia, ou estão interessados no assunto, ou, ainda, estão se preparando para realizar tal procedimento.

Pesquisas utilizando as redes sociais on-line - e, mais especificamente, o Facebook - têm se tornado comum em âmbito nacional (ver DONNA; SILVA, 2014; FERREIRA; LEÃO; PAIVA JÚNIOR, 2014; NASCIMENTO et al., 2015; SOARES; MONTEIRO, 2015; e HAHN et al., 2016, entre outros) e internacional (CASTELEYN; MOTTART; RUTTEN, 2009; ACKLAND, 2009; BROWN; VAUGHN, 2011; e DEKAY, 2012, entre outros). Para Ackland (2009) e Uhrig et al. (2010), as redes sociais on-line, como o Facebook, oferecem muitas oportunidades para pesquisas empíricas no campo social. Kozinets (2002) denomina de netnografia os estudos realizados em comunidades virtuais, considerando que são uma fonte relevante para estudos na área de marketing e alertando para os aspectos éticos a serem observados como a permissão dos membros da rede para participação neles.

Com o objetivo de obter material empírico sobre as manifestações de preconceitos contra os obesos no ambiente de trabalho, elaboramos um formulário composto por quatro questões de múltipla escolha e quatro dissertativas. A aplicação do instrumento foi disponibilizada on-line, por meio do aplicativo Google Docs, para que todos os membros do grupo selecionado no Facebook pudessem preencher individualmente. Nossa escolha por considerar uma rede social on-line se deveu ao fato de esse ser um veículo utilizado para mobilização social, portanto um lócus relevante: "É nas redes sociais que obesos, gorduchos e simpatizantes começam a se mobilizar para afirmar o orgulho gordo" (BIDERMAN, 2011). O contato com os respondentes e o convite para participação no levantamento foram realizados por meio da mídia social, e o formulário ficou disponível durante o mês de janeiro de 2015. Os 290 voluntários, identificados nesta pesquisa com a letra P seguida do número sequencial $(\mathrm{Px})$, responderam a todas as questões.

Após a aplicação dos formulários, interpretamos as respostas dos participantes por meio da quantificação das questões fechadas e da análise de conteúdo das questões abertas, conforme Bardin (2011). 


\section{RESULTADOS}

Nesta seção, apresentamos os resultados da pesquisa em duas etapas: inicialmente, a quantificação das respostas de questões fechadas, para o que foi utilizado o software MS Excel; sem seguida, a interpretação por meio da análise categorial, conforme Bardin (2011).

\subsection{Impressões gerais dos respondentes sobre a obesidade}

Solicitamos aos respondentes que apontassem, em uma escala de 1 a 10, o grau em que as pessoas obesas se sentiam pressionadas para emagrecer. As respostas de 1 a 3 significavam grau fraco, de 4 a 7 (grau moderado) e de 8 a 10 (grau forte). Conforme a Tabela 1, acerca da pressão sofrida para emagrecer, a maioria $(81,7 \%)$ apontou que os obesos são fortemente pressionados para emagrecer; $14,5 \%$ disseram ser pressionados moderadamente; e $3,8 \%$ responderam serem fracamente pressionados para emagrecer.

Tabela 1: Sobre a pressão social para emagrecer

\begin{tabular}{ccc}
\hline Grau & Quantidade & $\mathbf{\%}$ \\
\hline Fracamente & 11 & 3,8 \\
Moderadamente & 42 & 14,50 \\
Fortemente & 237 & 81,7 \\
\hline Total & 290 & 100 \\
\hline
\end{tabular}

Fonte: Dados da pesquisa.

A segunda questão procurou identificar se os respondentes reconheciam a existência do preconceito contra pessoas obesas. Apenas duas pessoas $(0,7 \%)$ responderam negativamente, ao passo que a maioria indicou que o preconceito contra a obesidade existe na sociedade.

Quanto à terceira questão, quando perguntados se contratariam uma pessoa obesa para trabalhar, 4,9\% dos respondentes disseram que não, já a maioria $(95,1 \%)$ afirmou que sim. Esses resultados apontam que a estigmatização da obesidade se manifesta não apenas no âmbito social, mas, em diversos contextos, com destaque para a própria pessoa obesa. Ou seja, a percepção negativa atribuída à aparência física do corpo obeso incide sobre esses sujeitos de tal forma que, por insatisfação com a própria aparência, eles apresentam autorrejeição. Desse modo, vê-se a presença do preconceito da pessoa entrevistada em relação a si mesma e a outros obesos. 
A quarta questão solicitou que os respondentes assinalassem, em uma escala de 1 a 10, quão decisiva era a aparência em uma entrevista de emprego. Os dados apontam que 37,3\% responderam que era fortemente decisiva, 9,1\% disseram considerar moderada, e 2,1\%, fracamente decisiva. Isso permite inferir que, no que diz respeito à contratação de obesos, o receio de serem estigmatizados e discriminados por recrutadores é grande e, por consequência, tende a prejudicar a vida desses sujeitos no que se refere à remuneração, bem como a possíveis promoções.

Essa questão permitia a inclusão de comentários, os quais reforçaram algumas constatações já existentes acerca do processo socialmente construído de estigmatização da obesidade. Conforme a visão dos respondentes, é notório que, de acordo com as convenções sociais contemporâneas, o excesso de peso pode restringir o mercado de trabalho, sobretudo concernente à contratação e à remuneração, o que já foi encontrado por Rothblum (1992) e Puhl e Heuer (2009). As respostas apontam também que é forte a cobrança social para o alcance do corpo magro e, por conseguinte, a discriminação com os indivíduos obesos, corroborando pesquisas anteriores (NOVAES, 2006).

\subsection{Interpretações dos respondentes sobre as manifestações do preconceito contra a obesidade}

Antes do processo de formação de categorias, realizamos, considerando as orientações de Bardin (2011), uma leitura flutuante das respostas obtidas e, posteriormente, identificamos, nas respostas das questões abertas, palavras, frases e parágrafos significativos. Assim, para todas as respostas submetidas no questionário, tendo como base a revisão da literatura, atribuímos uma palavra-chave que representa o conteúdo principal da fala do entrevistado. Ainda conforme Bardin (2011), elaboramos o resumo dos parágrafos que, por estarem centrados em conteúdos correlatos, resultam na primeira codificação, considerando os parágrafos as unidades de registro.

A análise das respostas abertas aponta para 24 temáticas ou categorias iniciais vinculadas aos preconceitos contra os obesos na esfera do trabalho. Cada categoria constitui-se, portanto, de características comuns nas palavras que a formam. As 24 categorias iniciais foram aglutinadas em temáticas relacionadas, originando, assim, um segundo nível de interpretação, de caráter mais abrangente, composto por quatro categorias intermediárias, as quais, por sua vez, resultaram em três categorias finais. O Quadro 1 ilustra o processo de derivação das categorias finais. 
Quadro 1: Unidades de análise e categorias oriundas da análise de conteúdo

\begin{tabular}{|l|l|}
\hline Categorias finais & Categorias iniciais \\
\hline 1. A abominação & 1. Limitações impostas pelas comorbidades \\
& 2. Implicações na saúde física e mental \\
& 3. Limitações do corpo obeso \\
& 4. Qualidade de vida em jogo \\
2. Cultura do corpo ideal e perfeito
\end{tabular}

Fonte: Elaborado pelas autoras.

\subsubsection{As categorias finais}

Três categorias finais resultaram do processo de análise de conteúdo dos depoimentos obtidos nesta pesquisa: abominação do corpo obeso; o corpo obeso como fracasso; e a incapacidade do corpo obeso. A seguir, essas categorias são explicadas.

\subsubsection{Abominação do corpo obeso}

A primeira categoria final é a abominação do corpo obeso, cujo conceito norteador foram questões relacionadas à saúde do corpo obeso e às 
limitações impostas pelo excesso de peso. Assim, ela compreende os depoimentos em que a relação entre a obesidade e o desenvolvimento de doenças, ou as limitações físicas associadas ao excesso de peso são mencionados, como ilustrado nas falas a seguir.

[...] Fui ao médico e os resultados dos meus exames me assustaram. (P.17)

Ainda não fiz a cirurgia, mas meu sonho é fazer. Sofro muito preconceito, por conta disto tenho depressão, não gosto de sair, tenho vergonha, sem falar na pressão alta, asma, colesterol alto e outras coisas. (P.47)

O maior motivo para emagrecer é a saúde. Tenho sérios problemas na coluna e é fundamental realizar a cirurgia para ajudar a eliminar o sobrepeso. (P.157)

Pressão alta, diabetes, ácido-úrico, apneia do sono, artrose nos joelhos, falta de mobilidade, cansaço... (P.200)

Em muitos depoimentos, a situação de saúde foi considerada elemento preditor na decisão pela cirurgia bariátrica, um procedimento recomendado para sanar as doenças associadas à obesidade. Outros participantes afirmaram que as limitações físicas decorrentes do excesso de peso e das comorbidades os impediam de realizar atividades da vida diária, tais como trabalhar, se locomover, utilizar o transporte público, realizar os serviços domésticos, ter relações sexuais, brincar com os filhos e cuidar da sua higiene e saúde. O comprometimento das atividades laborais, com o declínio da saúde física, se traduz nas respostas a seguir:

No meu caso a obesidade estava atrapalhando o meu desempenho no trabalho. Dores nas articulações da perna, tornozelo, dificuldades para caminhar, enfim, para uma professora isso é terrível. Mas, além da saúde, me bateu uma vontade enorme de mudar meu visual também. Viajo muito a congressos, e estava difícil sentar nas poltronas dos aviões, dos ônibus, enfim, a obesidade estava me atrapalhando demais. (P.70)

No trabalho tinha restrições físicas e faltava por problemas de saúde. (P.90) 
Eu sempre fui gorda e não me atrapalhava em nada nos meus afazeres, atrapalhava mais os outros que a mim mesmo. (P.257)

Nos depoimentos, identificamos ainda uma relação estabelecida entre o corpo obeso e as dificuldades de casar e engravidar, o que revela o alcance da desqualificação do corpo da pessoa nessa condição:

Sonho em ser mãe, e, uma gestação obesa não é saudável. (P.180)

Fui fazer a ultrassom do meu terceiro filho, grávida e obesa, e eu perguntei sobre o sexo do bebê, ele disse que não adiantava eu querer ver, por ser gorda eu somente conseguiria ver depois dos 6 meses e olha lá. (P.231)

Essa categoria está diretamente ligada ao que os respondentes consideram como corpo ideal. O que eles dizem, conforme mostrado a seguir, expressa reações diversas ao que é o corpo "socialmente" aceitável:

O corpo ideal, na minha opinião é o reflexo de um interior bem cuidado. Passa pela saúde, bem-estar psicológico. Hoje eu acho que o meu corpo é o ideal para mim. (P.24)

[...] Meu corpo é uma aberração. (P.66)

O corpo ideal é aquele que te permite realizar as tarefas do dia a dia sem limitações, um corpo funcional. Porém devido à pressão da sociedade por mulheres cada vez mais magras acabo tendendo a querer ser magra também simplesmente pra não me destacar e ser alvo de críticas. (P.108)

Um corpo baseado no da Ivete Sangalo. (P.116)

Musculatura dura, barriga chapada, seios perfeitos (siliconados), sem estrias! (P.149)

A facilidade em realizar atividades cotidianas em decorrência da perda de peso foi destacada por vários respondentes ao descreverem o corpo perfeito, como ilustram os depoimentos dos participantes P.54 e P.210: 
Para mim, corpo ideal é aquele que lhe permite viver bem e a desempenhar as suas atividades de forma satisfatória. Há obesos bem ágeis e dinâmicos, como também há magros sedentários e lentos. (P.54)

Aquele em que eu consiga me abaixar e amarrar os sapatos. O que eu consiga subir dois lances de escada e não sinta que vou morrer de falta de ar. O corpo em que eu não precise de ajuda para fechar o fecho de uma saia, pois não tenho flexibilidade necessária para tal. O que eu consiga caminhar, correr, nadar sem me sentir mal. Enfim, o corpo ideal é aquele em que você consiga ter domínio das suas atividades, por mínima que seja. (P.210)

Assim, é possível dizer, com base nos relatos dos respondentes, o quanto as limitações físicas provocadas pela obesidade restringem os participantes da pesquisa em seus costumes e hábitos, forçando-os a realizar determinadas funções de outra forma, ou, até mesmo, deixar de fazê-las. No grupo pesquisado, a obesidade afetou tanto a execução de funções diárias quanto a saúde e a aparência física.

A abominação do corpo, conforme Goffman (1975), se refere a deformidades físicas que são estigmatizadas, um processo que ocorre sempre que existem normas de identidade. No caso da obesidade, a norma social é que o corpo obeso está associado a doenças, e por ser a obesidade uma condição visível no indivíduo, ela se equipara a uma deformidade. Ainda, essa marca visível torna o sujeito desacreditado (GOFFMAN, 1975), o que faz com que seja mais difícil quebrar o estigma (MELO, 2000), causando dano psicológico ao estigmatizado.

\subsubsection{0 corpo obeso como fracasso}

A segunda categoria final, o corpo obeso como fracasso, diz respeito à perspectiva que os obesos têm sobre o próprio corpo em termos de estética e aparência física. Os conceitos norteadores são vistos nos trechos que evidenciam sentimentos dos respondentes sobre a obesidade como um problema moral e estético e apresentam a autoimagem negativa incorporada com base na opressão que a sociedade exerce sobre essas pessoas.

A valorização do corpo na sociedade contemporânea elevou a luta pela boa forma a uma compulsão (BAUMAN, 2008), tornando os corpos não magros um símbolo do fracasso (BAUDRILLARD, 2005). Os sentimentos 
negativos expressados pelos depoentes ao falarem sobre seu corpo fazem alusão à obesidade como um problema de ordem moral e estética e reportam sentimentos de autoexclusão e autodesvalorização, como se pode verificar nos seguintes relatos:

Tô me sentindo horrível. (P.25)

Estava com vergonha de mim mesma. (P.93)

[...] Me sentia amargurada, triste, incapaz. Eu me sentia um peixe fora d'água, que não podia viver nessa sociedade se não atendesse aos padrões. (P.149)

[...] Autoestima baixa demais e horror ao espelho (não olhava um espelho de corpo inteiro há anos), me sentia um lixo, um patinho feio, parece que eu era o centro das atenções, por isso abandonei a vida social. (P.201)

Não me aceitava, já tinha tentado de tudo, ser vítima de preconceito desde a infância resultou em muita falta de autoestima, bulimia, depressão. (P.202)

Me sinto mal e rejeitada. (P.269)

Pode-se perceber como a estigmatização da obesidade afeta negativamente a autoimagem desses sujeitos, os quais, por vergonha e preconceito em relação à própria situação, passam a evitar contatos sociais. Observa-se a criação de um mecanismo de autoexclusão nas falas dos participantes, pois o corpo obeso não tem o capital simbólico (BOURDIEU, 2007) que o corpo magro adquiriu na sociedade contemporânea. A falta de autoestima em relação à sua imagem corporal foi um fator destacado como motivador para a gastroplastia. Os respondentes reportam sentimentos de mágoa e de inferioridade, além de vergonha, baixa autoestima e falta de amor próprio ao falar sobre como percebiam seu corpo na fase de obesidade:

Vergonha do meu corpo, vergonha de as pessoas olharem como se eu fosse um monstro. (P.87) 
Descontentamento com meu corpo e vergonha das pessoas. Baixa autoestima e falta de amor próprio. (P.104)

Baixa autoestima, vergonha de sair na rua, vergonha de ir a qualquer lugar [...]. (P.184)

Em nossa interpretação, os respondentes desenvolvem um autoconceito negativo, enfatizado pela vivência do estigma. Destacamos que os sentimentos e a imagem construída por eles acerca do corpo obeso se baseiam no modelo estético contemporâneo, o qual, de acordo com Pelegrini (2006, p. 2), "idealiza corpos excessivamente magros ou musculosos". Nesse sentido, a insatisfação das pessoas obesas desdobra-se em um estado de humor conhecido como disforia e provoca o isolamento social, uma das consequências do estigma (GOFFMAN, 1975). Partindo-se dessa reflexão, a vivência e a influência de atitudes preconceituosas contra o excesso de peso, serão analisadas e discutidas a seguir.

Evidencia-se que, entre os participantes da pesquisa, a maioria (59,05\%) não relatou ter problemas de saúde e atribuiu a tomada de decisão pela cirurgia bariátrica a outros aspectos. O público pesquisado enfatizou a discriminação em relação ao corpo obeso, avesso aos padrões ditados pela sociedade, como elemento principal no processo decisório. Essa perspectiva é expressa nos depoimentos:

Principalmente o preconceito, nunca tive problemas de saúde pelo peso. Mas o jeito como as pessoas olham para quem está fora dos padrões criados é o que mais incomoda. (P.2)

Por estar acima do peso não consigo tomar posse em emprego público. Foi mais por esse motivo que resolvi emagrecer. Meus exames de saúde são normais. (P.219)

Já passei por muitas situações constrangedoras e humilhantes e quero estar 'magra' para não me submeter mais a esse preconceito. (P.272)

Essa categoria explicita, de fato, a percepção dos obesos como vítimas de preconceito e de discriminação por grande parte da sociedade. Conforme os depoimentos, a estigmatização acentuou o isolamento dos depoentes 
que, após a exposição a atos desse tipo, desenvolveram sentimentos de baixa autoestima, vergonha, mágoa, tristeza, culpa, desconforto, desvalorização e solidão, o que Goffman (1975) alude ser a deterioração da identidade.

As respostas dos formulários são indicativas de que a dor de se ver "excluído socialmente" (P.53) e a vontade de ser "normal perante a sociedade" (P.146) foram fatores preponderantes para a realização da gastroplastia. Isso porque a beleza passou a ser adquirível (BAUDRILARD, 2005). Os depoimentos a seguir ilustram a busca dos respondentes por serem socialmente aceitáveis:

Ser aceito pela sociedade, me sentir parte do grupo do trabalho, dos relacionamentos. (P.51)

O preconceito, as brincadeiras de mau gosto, eu podia ser a melhor pessoa do mundo, mas para eles tinha um defeito: a gordura. (P.114)

Ser vista como diferente, como irreal, como se a obesidade fosse contagiosa. Quero andar na rua e não ser apontada, como referência. (P.157)

Estética mesmo, até em meio ao trabalho já sofri discriminação por conta de meu peso. Geralmente as pessoas acima do peso como eu fui um dia, até na vida pessoal, se sofre, somos vistos de uma certa forma como aberrações e isto nos humilha muito. Muitas das vezes não somos gordos porque queremos e sim porque temos algum distúrbio alimentar ou de hormônios. Mas certas pessoas não conseguem entender isto. (P.163)

O motivo principal foi o preconceito em todas as áreas: profissional e social. Problemas no trabalho, para fazer amigos, para arrumar namorado, para ir à praia, para ir a lugares muito quentes, para comprar roupa, para andar de condução, para comer em locais públicos ou no refeitório do trabalho e uma centena de situações que poderia listar eternamente aqui. (P.256)

Eu e minha esposa sofremos muito preconceito, tanto no trabalho (ela não conseguia ser promovida por nada) e nas academias/restaurantes/ lojas de roupas. Mal esperavam nós dois chegarmos perto pra falarem que não tinha vagas, ou que não tinha nosso tamanho de roupa... Quando chegávamos nos lugares o preconceito era nítido. (P.57) 
Conforme Bourdieu (2007), o corpo é um espaço para inscrição da condenação ao social. Essa condenação é recorrente em comentários desagradáveis, olhares hostis e piadas sobre o suposto excesso de peso. Por exemplo: "o meu sobrepeso incomoda mais os outros do que a mim mesma" (P.24). Os relatos mostram como essas críticas alteravam o estado de humor e os sentimentos dessas pessoas em relação a si mesmas:

Me sinto humilhada. É como se o obeso não fosse inteligente e capaz. (P.38)

[...] Magoada e deprimida. Sinto como se tivesse tido a minha dignidade roubada! (P.51)

No momento da piada dou risadas também só para disfarçar mesmo porque se notam que não gostei aí a zoação é maior, mas quando chego em casa as vezes até choro! (P.81)

[...] Inúmeras piadas e olhares preconceituosos. Chorava e me sentia inferior. (P.213)

Me chateia, me sinto diminuído, com vontade de sumir. (P.241)

Assim, os relatos apresentados mostram que, quando os obesos internalizavam os estereótipos presentes nos comentários negativos, eles se sentiam inferiorizados, humilhados, constrangidos e deprimidos (PUHL; HEUER, 2009). O medo do julgamento social e o constrangimento relativos à aparência física do corpo obeso conduziram essas pessoas ao isolamento, "com vontade de sumir", caracterizando o processo de estigmatização.

Ademais, pela análise dos depoimentos, notou-se que, durante o período de obesidade, os respondentes vivenciaram situações de discriminação no âmbito pessoal e social pelo fato de sua imagem corporal não corresponder aos padrões estéticos vigentes. Pode-se afirmar, então, que a estigmatização se estende a ambientes de lazer, de alimentação, aos meios de transporte e, principalmente, às lojas de roupas e ao ambiente de trabalho. A obesidade é então um estigma, uma marca que a sociedade imputa ao obeso (MELO, 2000), limitando sua capacidade de agir. 
O fracasso de não conseguir ser magro causa nos obesos o sentimento de culpa, o que, conforme Baudrillard (2005), leva a práticas extremas, como as cirurgias para correção, que é o caso da gastroplastia.

\subsubsection{A incapacidade do corpo obeso}

A terceira categoria final é a incapacidade do corpo obeso, que tem como conceito norteador a percepção dos participantes da pesquisa quanto às dificuldades enfrentadas no que concerne ao ambiente de trabalho, promoções e remuneração.

Em muitos depoimentos, foi recorrente a menção a processos discriminatórios vivenciados pelos respondentes, como ilustram os trechos a seguir:

Fui fazer entrevista para uma loja de artigos esportivos, e me falaram que só podiam me contratar depois que emagrecesse por causa do segmento da loja. Fiquei arrasada. (P.59)

As inúmeras tentativas frustradas de ingressar no mercado de trabalho e sendo vetada pela área técnica julgar que não seria capaz de desenvolver tal atividade por ser obesa. Passar por vários processos seletivos e na parte de exames médicos ser cortada por causa de relação peso x altura. (P.175)

Em vários locais disseram que uma "apresentação" melhor me ajudaria a conseguir um emprego e que eu era muito competente, mas que para o cargo em questão era necessária boa aparência física. (P.242)

Fui entregar um currículo numa loja de roupas, a mocinha me olhou de cima para baixo e disse esse cargo é para moças pequenas, daí eu perguntei a ela: 'como assim?'. Ela, sem meias palavras, disse: 'Gente magra, senão não atrai a atenção dos clientes'. Saí de lá com um nó na garganta e então eu decidi mudar de vida. (P.268)

A discriminação por parte dos profissionais recrutadores e outros, de forma explícita ou velada, foi uma categoria destacada pelo grupo entrevistado, corroborando as afirmações de Puhl e Heuer (2009). A estigmatização do corpo obeso, em uma entrevista de emprego, se sobressai às competências 
profissionais, criando uma barreira que resulta na perda da oportunidade de trabalho, como se pode verificar nos depoimentos a seguir:

[...] Já perdi ofertas de emprego só por ser obeso, era qualificado, tinha experiência e ainda sim selecionaram um novato que nunca tinha trabalhado com aquilo na vida. (P.22)

Quando me ligaram para a entrevista, disseram que meu currículo era o melhor que tinham visto. Porém, após a entrevista ao vivo, fui substituída por uma menina menos capaz e mais magra. (P.33)

[...] Tinha ótima qualificação (mestrado, doutorado, 2 especializações e 10 anos de docência). Fui aprovada, mas na entrevista perguntaram o motivo e há quanto tempo estava tão acima do peso. Após a entrevista, fui dispensada. (P.51)

As escolas não dão emprego para mim. Sou formada em pedagogia, mas, no entanto, sou gorda e eles dizem que meu perfil não se encaixa. (P.56)

Fui a uma entrevista de trabalho, quando o entrevistador me viu, nem me deixou sentar, despachou logo de cara, disse que o trabalho não dava para mim. (P.68)

Eu fui considerada pronta, estava preparada, passei por todas as fases de um curso para gerente, porém na entrevista os meus superiores me elogiaram mas não consideram apta. Eu entendi na hora a questão do peso. (P.89).

Pois, mesmo bem qualificada, não fui contratada e pessoas menos qualificadas foram, depois percebi que não havia funcionários obesos ou sobrepeso na empresa. (P.102)

Esse aspecto também pode ser exemplificado no depoimento de P.12, quando afirma que "o problema é na hora de ser contratado. Tudo muda na hora da entrevista de emprego". De forma geral, pode-se constatar que 
a estética serviu como elemento determinante para a não contratação dos obesos, e, de fato, eram proferidas declarações ofensivas que os constrangiam:

Quem estava fazendo o processo disse que os obesos são pessoas que sempre quebram cadeiras e interrompem o trabalho para comer muitas vezes por dia. (P.18)

Olharam para ela e falaram que obesas como ela geralmente são molengas e não dão conta do serviço direito. (P.36)

A entrevistadora falou claramente que para trabalhar na loja teria que ser uma pessoa com biótipo magro, pois, as clientes da loja eram assim... (P.86)

Fiz uma entrevista para uma empresa bem-conceituada no ramo de planos de saúde, a pessoa que estava fazendo a seleção gostou muito do meu currículo, porém me disse que eu não tinha perfil físico para a vaga. Me senti muito humilhada!! (P.129)

Eu mesma, quando obesa, fiz uma entrevista de emprego onde a dona da loja deixou claro que, por eu estar acima do peso não tinha perfil para trabalhar na loja de roupas masculinas, porque os clientes preferem mulheres com a silhueta em dia. Me senti mal e fiquei chateada. (P.166)

Estava desempregada, e mesmo sendo qualificada para a vaga não era contratada. Em uma situação o patrão da minha mãe chegou a dizer para ela que não me contrataria por ser gorda e sendo assim não passaria uma boa imagem da empresa. (P.203)

Puhl e Heuer (2009) apontam em sua pesquisa que a obesidade é estigmatizada como preguiça, incompetência, falta de capacidade e outros atributos negativos. A incapacidade do corpo obeso é um estigma evidenciado nos processos seletivos, o que fez com que alguns depoentes desistissem de trabalhar, como mostrado nos depoimentos de P.297, P.50, P. 61 e P.211: 
[...] Ela me disse na minha cara que não podia me contratar porque eu era obesa, fiquei com muita vergonha e não tive coragem de dizer nada e fui embora chorando e não contei para ninguém, na época, em 95, nem se comentava muito sobre o preconceito... Foi muito ruim... Tanto que nunca mais fui procurar emprego em lojas. (P.297)

Já me falaram que não posso assumir um cargo de chefia da empresa por não saber me vestir bem por ser obesa. (P.50)

Um colega recebeu um ultimato. Era representante de uma multinacional ou emagrecia ou iria ser demitido. (P.61)

Eu perdi o meu emprego por estar obesa, a minha chefe foi clara nisso. (P.211)

Com a falha em diversas tentativas de inserir-se no mercado de trabalho, os respondentes enxergam as organizações como ambientes de ameaça, frustração e sem estabilidade, pois, quando contratados, o resultado de seu trabalho sempre é julgado como sendo inferior ao de indivíduos mais magros. Assim, o obeso vê sua identidade deteriorada, no sentido de Goffman (1975).

É interessante notar como a imagem negativa do profissional obeso é incorporada como verdade, também, por ele mesmo. Baudrillard (2005) refere-se a esse processo como "ditadura da beleza". Os depoimentos a seguir apontam para essa ideia.

Hoje me assusto quando vejo alguém muito acima do peso e lembrome que eu era até pior!!!!!!!!! Mas, para trabalho, julgaria mais a aparência no sentido higiene e comportamento do que peso. Se 2 candidatos fossem iguais, mas um magro e outro muito gordo, acho que ficaria com o magro... (P.178)

Conheço pessoas que tinham currículos favoráveis, mas não foram contratadas por estar com obesidade mórbida. Trabalhei em RH como recrutadora e a empresa me impediu de contratar devido a isso. (P.213)

Minha resposta pode parecer hipocrisia com o que estou escrevendo aqui, mas, eu fui específica quanto à aparência exterior (não a obesi- 
dade), pois, hoje sou empresária e não contrataria, nunca, uma menina que não soubesse se sentar de uma forma decente para uma recepção, por exemplo. (P.264)

$\mathrm{Na}$ sociedade contemporânea, o corpo se tornou um valor cultural que integra o indivíduo a um grupo (FELERICO, 2009). Assim, para que ele se integre, tanto no âmbito do trabalho como no dos relacionamentos sociais e amorosos, é preciso dirigir um esforço para atender à normal social de ter cuidados com o corpo para torná-lo ou mantê-lo magro.

Os relatos analisados demonstram que na iniciativa pública e também na privada os obesos são profundamente estigmatizados, uma vez que suas qualificações técnicas não são reconhecidas pelos outros profissionais. As possibilidades de contratação, crescimento, remuneração e realização são comprometidas, o que resulta na incorporação, por parte do obeso, do sentimento de desvalia associado ao de desvalorização, situando-se este na condição de desacreditado, conforme a perspectiva de Goffman (1975). Para além das questões anteriormente levantadas, destaca-se que o desenvolvimento pessoal e profissional do obeso é comprometido com essas manifestações de discriminação.

\section{CONSIDERAÇõeS FINAIS}

Esta pesquisa sobre a obesidade no contexto organizacional procurou desvelar, por meio das respostas dos 290 participantes, o preconceito social e as limitações vivenciadas por esses indivíduos ao longo de sua trajetória no mercado de trabalho. Nossa reflexão foi conduzida pelos pressupostos da análise de conteúdo, o que possibilitou a identificação de três categorias finais: (1) a abominação do corpo obeso, (2) o corpo obeso como fracasso e (3) a incapacidade do corpo obeso. Os resultados deste estudo indicaram a construção social do corpo na sociedade contemporânea, que, ao estabelecer padrões de beleza pelos quais a magreza é sinônimo de beleza e o culto ao corpo é de responsabilidade da pessoa, inscreve a obesidade nas duas primeiras circunstâncias: (1) é uma abominação do corpo e (2) provoca sentimento de culpa e vergonha. Além disso, a pessoa obesa carrega o estigma de ser incapaz.

Em alguns relatos, a obesidade mórbida representava agravos à saúde. Essas comorbidades, decorrentes do excesso de gordura e peso, geravam restrições físicas diversas que diminuíam, drasticamente, a qualidade de vida 
dos depoentes e alteravam o seu cotidiano. A falta de mobilidade e, por consequência, a de agilidade foram assinaladas como fator decisivo pelos recrutadores na não contratação dessas pessoas. Contudo, foi apontado, por meio dos depoimentos, que a maioria dos obesos não apresentava uma situação de saúde vulnerável, e, mesmo nesses casos, sua capacidade produtiva não se alterava.

Outro ponto relevante para os respondentes foi a relação de insatisfação estabelecida com o corpo obeso e uma autoimagem negativa. A concepção dos participantes da pesquisa em relação à obesidade é baseada no padrão contemporâneo de beleza, que apresenta como referência o corpo jovem e magro. Por não corresponder a esse modelo criado pela sociedade ocidental, os sujeitos são rejeitados e estigmatizados como preguiçosos, egocêntricos, descontrolados, irresponsáveis, sem valor etc. Essa desmoralização, vivida em ambientes diversos, faz com que os obesos se sintam inferiorizados, inadequados, culpados, angustiados e envergonhados. No presente estudo, o julgamento social e o preconceito em relação à sua própria situação fizeram com que vários dos depoentes se isolassem do olhar alheio. Neste ínterim, a decisão dos participantes de submeter-se à gastroplastia pautou-se no preconceito social vivenciado.

Quanto à discriminação contra os obesos, é notório o fato de que o ambiente organizacional se constitui em uma fonte de estigma. A dificuldade na contratação, nas promoções e, consequentemente, na remuneração desmotivou o grupo pesquisado, que, após a exposição a atos desse tipo, reportou sentimentos de desconforto, rejeição, fracasso e culpabilização.

Esta pesquisa tem contribuições práticas e teóricas para os estudos sobre organizações e gestão de pessoas. Quanto às primeiras, aponta para a necessidade de políticas e práticas efetivas que considerem a obesidade no contexto organizacional não como um fator de risco, mas, sim, como parte da identidade das pessoas. Em termos teóricos, sinaliza que a obesidade é uma fonte de discriminação, legitimação de diferenciais de poder, além de promover tensões no contexto organizacional.

Assim, este estudo preenche uma lacuna nas pesquisas da área de gestão de pessoas e administração em geral, sinalizando um campo promissor a ser explorado. Nesse sentido, sugerimos direções de pesquisa sobre a temática: (1) estudos qualitativos sobre as ações e práticas empresariais orientadas à redução da obesidade dos empregados; (2) estudos de natureza etnográfica que investiguem os tipos de discriminação contra pessoas obesas, bem como 
as relações de poder; e (3) estudos que investiguem o estigma da obesidade como segregador de posições no ambiente de trabalho.

\section{REFERÊNCIAS}

ACKLAND, R. Social Network Services as Data Sources and Platforms for e-Researching Social Networks. Social Science Computer Review, v. 27, n. 4, p. 481-492, 2009.

BARBOSA, M. R.; MATOS, P. M.; COSTA, M. E. Um olhar sobre o corpo: o corpo ontem e hoje. Psicologia \& Sociedade, v. 23, n. 1, p. 24-34, 2011.

BARDIN, L. Análise de conteúdo. São Paulo: Edições 70, 2011.

BAUDRILLARD, J. A Sociedade de Consumo. Lisboa: Edições 70, 2005.

BAUMAN, Z. Vidas para consumo. São Paulo: Jorge Zahar Editor, 2008.

BIDERMAN, I. Orgulho gordo. Folha de S.Paulo. Equilíbrio. 29 mar. 2011. Disponível em: <http://www1.folha.uol.com.br/fsp/equilibrio/eq2903201107.htm >. Acesso em: 10 mar. 2016.

BRAY, G. A. History of obesity. In: WILLIAMS, G.; FRÜHBECK, G. Obesity: science to practice. Chichester: Wiley-Blackwell, 2009, p. 3-17BOURDIEU, P. A distinção: crítica social do julgamento. São Paulo: Edusp, 2007.

BROWN, V.; VAUGHN, D. The writing on the (Facebook) wall: the use of social networking sites in hiring decisions. Journal of Business and Psychology v. 26, p. 219-225, 2011.

BUCARETCHI, H. A. (Org.). Anorexia \& Bulimia Nervosa. São Paulo: Casa do Psicólogo, 2003.

CASTELEYN, J.; MOTTART, A.; RUTTEN, K. How to use Facebook in your market research. International Journal of Market Research v. 51, n. 4, p. 439-447, 2009.

COPPINI, L. Z. Nutrição e metabolismo em cirurgia metabólica e bariátrica. Rio de Janeiro: Rubio, 2015.

DAMASCENO, V. O. et al. Imagem corporal e corpo ideal. Revista Brasileira de Ciência e Movimento, v. 14, n. 1, p. 87-96, 2006.

DAOLIO, J. Da cultura do corpo. Campinas: Papirus, 1995.

DEKAY, S. H. How large companies react to negative Facebook comments. Corporate Communications: An International Journal, v. 17, n. 3, p. 289-299, 2012.

DE TOPLESS, modelos 'plus size' fazem protesto contra a 'gordofobia' em frente ao Congresso. Folha de S.Paulo, 15 nov. 2014. Disponível em: <http://f5.folha.uol.com.br/ voceviu/2014/11/1546768-de-topless-modelos-plus-size-fazem-protesto-contra-a-gordofobia-em-frente-ao-congresso.shtml>. Acesso em: 10 abr. 2016.

DONNA, C. U.; SILVA, A. R. L. Os usos do Facebook nas manifestações dos simbolismos organizacionais. REAd. Revista Eletrônica de Administração, v. 20, n. 3, p. 681-712, 2014.

FELERICO, S. A publicidade e seus corpos punidos. A reação da propaganda em oposição ao discurso publicitário da ditadura dos corpos ultramedidos. In: ENCONTRO NACIONAL DE HISTÓRIA DA MÍDIA, 7, Fortaleza, 2009. Anais... Associação Brasileira de Pesquisadores 
de História da Mídia: São Paulo, 2009. CDROM.

FERNANDES, F. Obesidade, o peso do preconceito. Superinteressante, Ciência, 30 set. 2001. Disponível em: http://super.abril.com.br/saude/obesidade-o-peso-do-preconceito/>. Acesso em: 10 abr. 2016.

FERREIRA, B. R. T.; LEÃO, A. L. M. S.; PAIVA JÚNIOR, F. G. Identificação e diferença na construção de identidades culturais de torcedores rivais dos três grandes clubes da cidade do Recife: entre a defesa e o ataque em interações sociais virtuais. PODIUM Sport, Leisure and Tourism Review, v. 3, n. 2, p. 85-96, 2014.

FISCHLER, C. Obeso benigno, obeso maligno. In: SANT'ANNA, D. B. (Org.). Políticas do Corpo: elementos para uma história das práticas corporais. São Paulo: Estação Liberdade, 1995.

GAYA, A. Será o corpo humano obsoleto? Sociologias, v. 13, p. 324-337, 2005.

GOFFMAN, E. Estigma: notas sobre a manipulação da identidade deteriorada. Rio de Janeiro: LTC, 1975.

GONÇALVES, M. A. S. Sentir, Pensar, Agir - Corporeidade e Educação. Campinas: Papirus, 1994.

HAHN, I. S. et al. Resposta emocional à publicidade em mídias sociais. Revista Pensamento Contemporâneo em Administração, v. 10, n. 1, p. 140-151, 2016.

HEILBORN, M. L. Fronteiras simbólicas: gênero, corpo e sexualidade. Cadernos Cepia no 5 , Rio de Janeiro, p. 73-92, dez. 2002.

KOZINETS, R. V. The field behind the screen: Using netnography for marketing research in online communities. Journal of Marketing Research, v. 39, n. 1, p. 61-73, 2002.

LEVAY, C. Obesity in organizational context. Human relations, v. 5, p. 1-21, 2013.

LORBER, J.; MARTIN, P. Y. The Socially Constructed Body: insights from feminist theory. In: KIVISTO, P. Illuminating Social Life: Classical and Contemporary Theory Revisited. London: Sage Publications, 2013, p. 249-273.MELO, Z. M. Estigma: espaço para exclusão social. Revista Symposium, v. 4 (especial), p. 18-22, 2000.

NASCIMENTO, M. C. R. et al. Com que cor eu vou pro shopping que você me convidou? Revista de Administração Contemporânea, v. 19 (3. ed. especial), p. 245-268, 2015.

NOVAES, J. V. O intolerável peso da feiura. Sobre as mulheres e seus corpos. Rio de Janeiro: Garamond, 2006.

PATARI, P. Empresas preferem contratar profissionais magros, diz pesquisa. Conteúdo GG. 2015. Disponível em: < https://oglobo.globo.com/economia/emprego/maioria-das-empresas-ainda-resiste-em-contratar-profissionais-com-mais-de-40-diz-pesquisa-14787771/>. Acesso em: 20 jun. 2015.

PUHL, R. M.; HEUER, C. A. The stigma of obesity: A review and update. Obesity, v. 17, p. 941-964, 2009.

PUHL, R.; BROWNELL, K. D. Obesity, bias, and discrimination. Obesity Research, v. 9, p. 788-805, 2001. 
PELEGRINI, T. Imagens do corpo: reflexões sobre as acepções corporais construídas pelas sociedades ocidentais. [Versão on-line]. Revista Urutágua, Maringá, n. 8. 2006. Disponível em: <www.urutagua.uem.br/008/08edu_pelegrini.htm>. Acesso em: 25 jul. 2015.

ROTHBLUM, E. D. The stigma of women's weight: Social and economic realities. Feminism \& Psychology, v. 2, n.1, p. 61-73, 1992.

SIEBERT, R. S. As relações de saber-poder sobre o corpo. In: ROMERO, E. (Org.). Corpo, mulher e sociedade. Campinas: SP: Papirus, 1995. p. 15-42.

SANTOLIN, C. B.; RIGO, L. C. O nascimento do discurso patologizante da obesidade. Movimento. Revista de Educação Física da UFGRS, v. 21, n. 1, p. 77-90, 2015.

SOARES, F. R.; MONTEIRO, P. R. R. Marketing digital e marketing de relacionamento: interação e engajamento como determinantes do crescimento de páginas do Facebook. NAVUS - Revista de Gestão e Tecnologia, v. 5, n. 3, p. 42-59, 2015.

STENZEL, L. M. Obesidade. O peso da exclusão. Porto Alegre: EDUPUCRS, 2003.

SYNNOTT, A. Tomb, Temple, Machine and Self: The Social Construction of the Body, The British Journal of Sociology, v. 43, n. 1, p. 79-110, 1992.

UHRIG, J. et al. Social Networking Websites as a Platform for Disseminating Social Marketing Interventions: an exploratory pilot study. Social Marketing Quarterly, v. 16, n. 1, p. 2-20, 2010.

VAZ, P. Consumo e risco: mídia e experiência do corpo na atualidade. Comunicação, Mídia e Consumo, v. 3, n. 6, p. 37-61, 2006.

VERÃO em excesso. Folha de S.Paulo. Revista Folha, 26 jan. 1997. Disponível em: < http:// www1.folha.uol.com.br/fsp/1997/1/26/revista_da_folha/4.html . Acesso em: 10 abr. 2016.

VIEIRA, L.; COHEN, M. Alunos acima do peso são mais vítimas de bullying na escola. $\mathbf{O}$ Globo. Educação, 4 maio 2014. Disponível em: https://oglobo.globo.com/sociedade/educacao/ alunos-acima-do-peso-sao-mais-vitimas-de-bullying-na-escola-12375170>. Acesso em: $10 \mathrm{abr}$. 2016.

WANDERLEY, E. N.; FERREIRA, V. A. Obesidade: uma perspectiva plural. Ciência e Saúde Coletiva, v. 15, n. 1, p. 185-194, 2010.

Recebido em: 24-11-2016

Aprovado em: 24-04-2017

Avaliado pelo sistema double blind review.

Editor: Elmo Tambosi Filho

Disponível em http://mjs.metodista.br/index.php/roc 